\title{
Perioperative dental screening and treatment in patients undergoing cardio-thoracic surgery and interventional cardiovascular procedures. A consensus report based on RAND/UCLA methodology 年
}

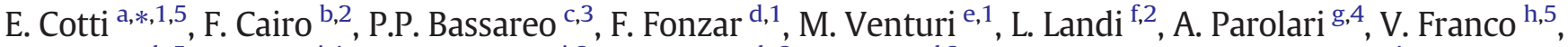

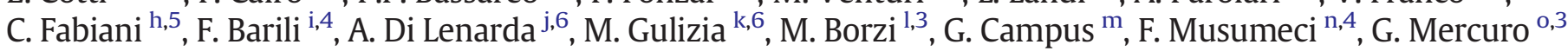 \\ a Department of Conservative Dentistry and Endodontics, University of Cagliari, Italy \\ ${ }^{\mathrm{b}}$ Research Unit in Periodontology and Periodontal Medicine, University of Florence, Italy \\ c University College of Dublin, Mater Misericordiae University Teaching Hospital, Dublin, Ireland \\ d Private practice, Udine, Italy \\ e Private practice, Bologna, Italy \\ ${ }^{\mathrm{f}}$ Private practice, Verona, Roma, Italy \\ ${ }^{g}$ Unit of Cardiac Surgery and Translational Researh, IRCCS Policlinico S. Donato, San Donato, Italy \\ ${ }^{\text {h }}$ Private practice, Roma, Italy

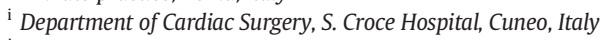 \\ j Cardiovascular Center ASS1, Trieste, Italy \\ k Division of Cardiology, Hospital "Garibaldi-Nesima", Catania, Italy \\ ${ }^{1}$ Department of Cardiovascular Disease, University of Rome Tor Vergata, Rome, Italy \\ ${ }^{m}$ Department of Surgery, Microsurgery and Medicine Sciences, University of Sassari, Italy \\ ${ }^{n}$ Department of Heart and Vessels, Cardiac Surgery Unit and Heart Transplantation Center, S. Camillo-Forlanini Hospital, Roma, Italy \\ ${ }^{\circ}$ Department of Medical Sciences, Cagliari, Italy
}

\section{A R T I C L E I N F O}

Available online 17 June 2019

\section{Keywords:}

RAND/UCLA appropriateness method

Inter-societies consensus

Dental screening

Cardiac surgery

\begin{abstract}
A B S T R A C T
Aim: To reach a consensus on a consistent strategy to adopt when screening patients for dental/periodontal infections, and on the feasibility of providing dental treatment before cardiothoracic surgery, cardiovascular surgery or other cardiovascular invasive procedures.

Methodology: A panel of experts from six Italian scientific societies was created. The deliberations of the panel were based on the RAND method. From an initial systematic literature review, it became clear that a consensually validated protocol for the reproducible dental screening of patients awaiting cardiac interventions was considered mandatory by professionals with expertise in the dental, cardiologic and cardiac surgery areas. However, systematic review also concluded that the treatment options to be provided, their prognosis and timing in relation to the physical condition of patients had never been defined. Following the systematic review several fundamental questions were generated. The panel was divided into two working groups each of which produced documents that addressed the topic and which were subsequently used to generate a questionnaire. Each member of the panel completed the questionnaire independently and then a panel discussion was held to reach a consensus on how best to manage patients with dental/periodontal infections who were awaiting invasive cardiac procedures.

Results: A high level of agreement was reached regarding all the items on the questionnaire, and each of the clinical questions formulated were answered. Three tables were created which can be used to generate a useful tool to provide standardized dental/periodontal screening of patients undergoing elective cardiovascular interventions, and to summarize both the possible oral and cardiovascular conditions of the patient and the timing available for the procedures considered.

Conclusions: Upon publication of this consensus document, the dissemination of the information to a wide dental and cardiac audience should commence. The authors hope that this consensus can become a model for the
\end{abstract}

\footnotetext{
is (c) 2018 Jointly by the International Endodontic Journal (Published by John Wiley \& sons Ltd) and Elsevier B.V. All rights reserved.

* Corresponding author at: Via Roma149, 09124 Cagliari, Italy.

E-mail address: cottiendo@gmail.com (E. Cotti).

1 Accademia Italiana di Endodonzia, AIE

2 Società Italiana di Parodontologia e Implantologia, SIdP

3 Società Italiana di Cardiologia, SIC

4 Società Italiana di Chirurgia Cardiaca, SICCH

5 Società Italiana di Endodonzia SIE

${ }^{6}$ Associazione Nazionale Medici Cardiologi Ospedalieri, ANMCO
} 
development of a dedicated protocol, ideally usable by heart and dental teams in the pre-interventional preparation phase.

(c) 2019 Elsevier B.V. All rights reserved.

\section{Introduction}

The screening of patients and the management of oral infections in patients undergoing cardiothoracic, vascular surgery or other cardiovascular (CV) invasive procedures is controversial. According to the guidelines of the European Society of Cardiology (ESC): it is "strongly recommended that potential sources of dental sepsis should be eliminated at least two weeks before implantation of a prosthetic valve or other intracardiac or intravascular foreign material, unless such procedures are urgent" [1]. The guidelines of the American Heart Association state: "a careful preoperative dental evaluation is recommended so that required dental treatment may be completed whenever possible before cardiac valve surgery, or replacement, or repair of congenital heart disease. Such measures may decrease the incidence of late prosthetic valve endocarditis caused by viridans group streptococci [2]. As a result of these guidelines, general dentists and specialist centres receive large numbers of requests for often urgent oral and dental assessment and treatment before heart surgery and invasive CV procedures.

Unfortunately, these various guidelines do not provide details of how a dental screening process should be undertaken, and neither do they define clearly what an oral or dental infection is, nor acknowledge it is often challenging to make an accurate diagnosis, particularly in endodontics, where early signs of infection and inflammation are not always recognizable.

Patients scheduled for an elective CV procedure can be referred to departments of dental-maxillofacial surgery, specialist hospital dental units, or to their general dentists for screening and possible treatment of an oral/dental infection. Since a variety of professionals are involved in this critical therapeutic phase for patients awaiting cardiac interventions, the absence of standardized protocols on how to carry out a comprehensive and accurate dental assessment (screening) and provide the necessary dental treatment, as well as how to manage cardiac patients is challenging and it would be helpful if standardized clinical recommendations were available for the dental management of patients awaiting these types of interventions.

The feasibility of providing appropriate dental treatment is connected to the status of the patient, the time available and the prognosis of the specific treatment that is required on each individual tooth. Unfortunately, dentists are not always informed of the timing of the cardiac intervention and cardiologists are most often unaware of the type, importance or complexity of the dental treatment that needs to be administered to their patients [3,4]. Basically, neither the cardiac specialist nor the dental team know whether the expected benefits of treating an oral/ dental infection in a patient with a severe CV condition outweighs the risks involved in the procedure [5].

In summary, even though the dental screening and treatment of patients who need elective cardiac surgery are recommended by the guidelines from the American Heart Association and the European Society of Cardiology there is no standard or general agreement on the oral and dental screening process or the specific dental treatments that need to be carried out immediately, or those that could be delayed until after the $\mathrm{CV}$ intervention. It could be speculated that, depending on who is involved in the dental management of the patient, they may be either carefully screened and treated to a high standard of care, or may receive a superficial screening that fails to identify sites of infection resulting in a waste of resources and time, low compliance to the guidelines and compromised outcomes for the patient.

The aim of this consensus project was to utilize a RAND process [6]. In order to reach agreement on a consistent and effective strategy to adopt for evaluating the presence of oral/dental infection, and on the feasibility of providing the necessary dental treatment before cardiothoracic or CV surgery or other CV invasive procedures.

\section{Methodology}

\subsection{Selection of the consensus panel}

Participants were selected from members of six Italian scientific societies: Italian Society of Cardiology, SIC (PPB, MB, GM); Italian Association of Hospital Cardiologists, ANMCO (ADL, MG); Italian Society of Cardiac Surgery, SICCH (AP, FB, FM); Italian Society of Periodontology, SIdP (FC, LL); Italian Society of Endodontics SIE (EC, CF, VF); Italian Academy of Endodontics AIE (MV, FF, EC). Each society selected the chairs and co-chairs. An external member (GC) provided methodological expertise for the RAND process.

\subsection{Consensus procedure}

The RAND/UCLA appropriateness method (RAM) [6] was selected to achieve consensus. The RAND is a modified Delphi method, approved by major institutes [7], developed to identify the collective opinion of experts and to enable the measurement of the use of medical/surgical procedures. Since consensus does not need to be defined as full agreement among participants, a pre-specified target of $80 \%$ agreement was approved.

\subsection{Consensus structuring}

The consensus process was divided into three phases (Fig. 1).

\subsubsection{Phase I}

2.3.1.1. Determining the purpose, scope, and intended audience. Initially, a systematic review was carried out to evaluate the information available on the three main questions:

Question 1. Is there agreement on the need for dental evaluation and treatment before $\mathrm{CV}$ interventions?

Question 2. Are consistent clinical recommendations or protocols available?

Question 3. What is the effectiveness of dental treatment prior to $\mathrm{CV}$ interventions?

A systematic electronic search of MEDLINE, Scopus and Web of Science was performed from the inceptions of the databases up to 31st April 2016. Searches were performed using Boolean operators to combine medical subject headings and free text words. Since this review included a large heterogeneous group of study designs and sources, the results were synthesized using a narrative approach.

Question 1 - Based on expert opinion it was concluded that there is general agreement on the need for screening and treatment of dental/periodontal infections in patients undergoing cardiac surgery and interventional $\mathrm{CV}$ procedures.

Question 2 - There are no shared and consistent clinical recommendations or protocols on how to screen patients and of the specific dental conditions that should be treated.

Question 3 - the risk-to-benefit ratio in performing these treatments was controversial [8]. 


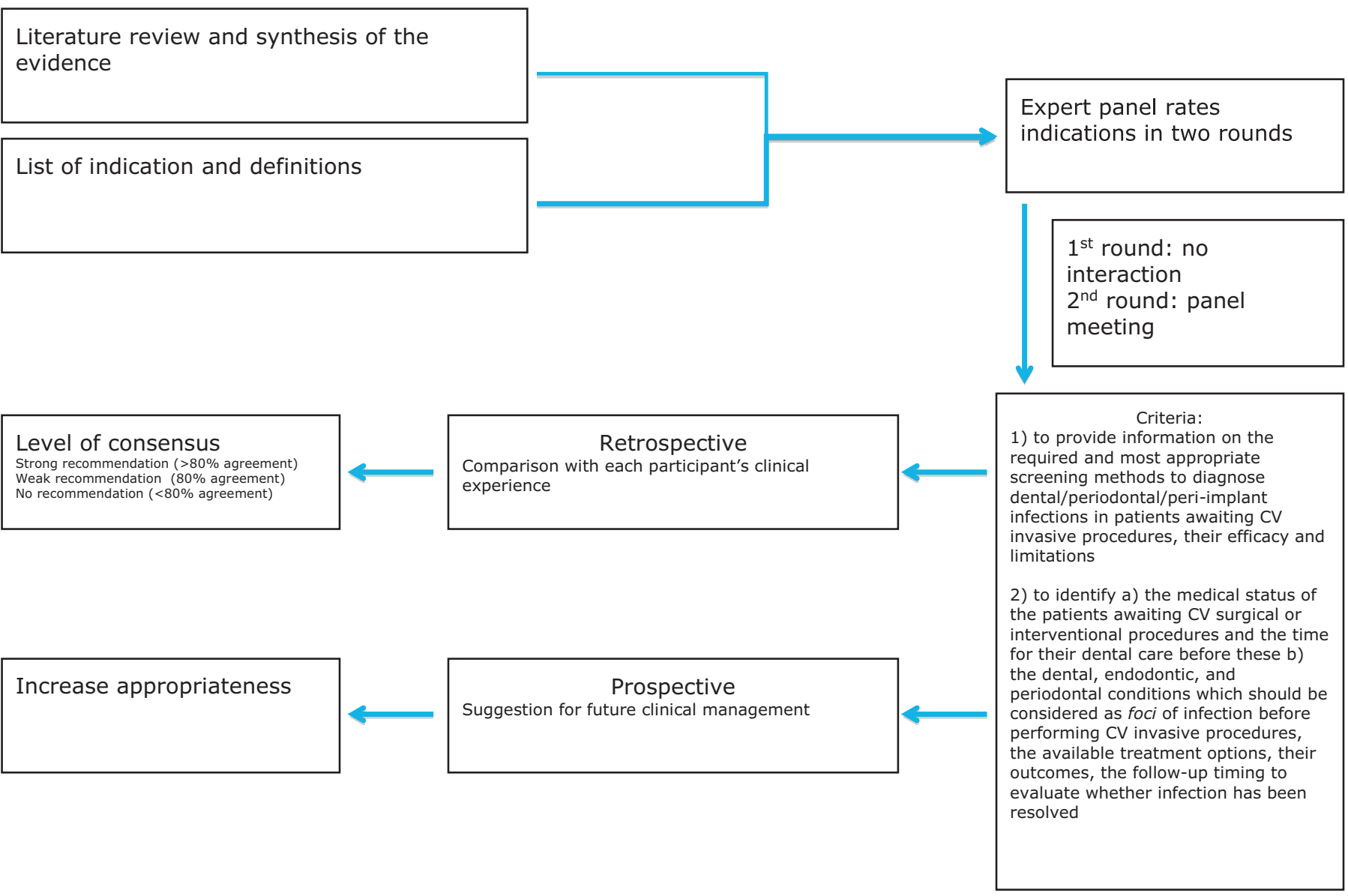

Fig. 1. The Rand scheme.

It was envisaged that the intended audience would be composed of all clinicians in the cardiac surgery, cardiology, and dental fields.

2.3.1.2. Selecting the panel of experts. A panel of experts, selected on the basis of research, academic and practical expertise, level of English language proficiency, were chosen from and represented the Italian scientific societies of Cardiology (SIC, ANMCO), Cardiac Surgery (SICCH), Periodontology (SIDP), and Endodontology (SIE, AIE).

2.3.1.3. Specifying the main focused clinical questions which the consensus process should answer, and decide on the relative importance of the outcomes. The issue was divided into the following three specific questions:

1. What would be a standardized clinical protocol for the assessment of the presence of infections of dental origin in a patient scheduled to undergo elective cardiac surgery or other invasive CV interventions?

2. What are the possible medical conditions of these patients and the time available for dental care (to define whether the indicated dental/periodontal intervention can be performed without harming the patient) based on their physical condition?

3. What are the periodontal and endodontic conditions that should be considered as foci of infections before performing the CV procedures, the treatment options available, their outcomes, and the follow-up timing needed to assess whether the infection has healed?

The panel of experts was then divided into two working groups, A and B. Group A was composed mainly of representatives of dental scientific societies and, to a lesser extent, representatives of cardiological/cardiac surgery societies ( 6 dentists, 1 cardiac surgeon and
1 cardiologist). It met to produce a document, shared and based on the best available scientific evidence, to provide information in response to Question 1 above. Group B, composed mainly of representatives of the cardiological and cardiac surgical societies (4 cardiologists, 2 cardiac surgeons and 2 dentists) met to produce a document, shared and based on the best available scientific evidence, to provide responses to Questions 2, and 3.

The documents produced by the two groups of experts were then transferred to the external member.

\subsubsection{Phase II}

2.3.2.1. Designing a questionnaire. On the basis of the documents produced by the two groups, the external member created a questionnaire, inviting the experts to rate the formulated questions (Fig. 2). Questions were submitted to members of each panel via a web-based system. To produce an overall score (1-10) for each question or cluster of questions, members were required to score the questions based on a Likert scale ranging from 1 (strongly disagree) to 10 (strongly agree) and to provide comments clarifying their answers.

\subsubsection{Phase III}

2.3.3.1. Consensus panel meeting. The panel reconvened to confirm the results of Phase II and to allow a face-to-face discussion. The experts were invited to discuss the results of the first round of the questionnaire and to declare whether or not they agreed with them. 


\begin{tabular}{|c|c|}
\hline 1. & $\begin{array}{l}\text { In cases of percutaneous transluminal coronary angioplasty are the microbes coming from skin those involved in the risk of infection therefore the } \\
\text { measures focused on oral health are negligible? }\end{array}$ \\
\hline 2. & Patients waiting for heart transplantation are not the most vulnerable among those undergoing surgery. \\
\hline 3. & The prognosis in patients with tricuspid regurgitation caused by infection (e.g. poor dentition, illicit drug use) is good. \\
\hline 4. & Asymptomatic patients, even with critical aortic stenosis, have an excellent prognosis for survival. \\
\hline 5. & Transplanted patients need to be placed in post-surgical immune-suppressive therapy, increasing the risk of infections. \\
\hline 6. & In severely compromised patients, the advantage of eliminating dental foci might be irrelevant. \\
\hline 7. & Tooth mobility should be assessed and verified overtime. \\
\hline 8. & Patient interview should look for any potential risk factors that may affect dental status. \\
\hline 9. & Inspective examination of oral, face and neck soft tissues is part of assessment for the presence of oral infections. \\
\hline 10. & To assess periodontal and peri-implant condition is important. \\
\hline 11. & $\begin{array}{l}\text { Among patients suffering from severe aortic regurgitation, those asymptomatic with decreased ejection fraction and those sympto matic } \\
\text { ficantly faster progression to death compared to asymptomatic subjects with normal ejection fraction. }\end{array}$ \\
\hline 12. & Once symptoms of heart failure develop, prognosis of mitral stenosis worsen dramatically. \\
\hline 13. & Isolated tenderness to palpation in the root apex area of a tooth is suggestive of relatively advanced periapical inflammation and/or infection. \\
\hline 14. & A full mouth BOP score below $25 \%$ may be considered compatible with a good periodontal stability. \\
\hline 15. & A tooth with irreversible pulpitis (deep caries) whether symptomatic or asymptomatic should be treated before surgery. \\
\hline 16. & Odontogenic and nonodontogenic pain should be differentiated. The pulpal or periodontal origin of the odontogenic pain must be established. \\
\hline 17. & Percussion testing is not a reliable technique for identifying inflammation in the periodontal ligament space. \\
\hline 18. & Tooth mobility, furcation involvement, bleeding on probing and plaque index will be also recorded in a dedicated periodontal chart. \\
\hline 19. & The Plaque Control should be performed. \\
\hline 20. & A positive response to the biting stress test is highly suggestive of periodontal inflammation or incomplete crown/root fracture. \\
\hline 21. & Interproximal flossing is not useful to detect caries or incongruous restorations. \\
\hline 22. & Palpation and percussion tests on teeth are important periodontal and endodontic screening tests. \\
\hline 23. & $\begin{array}{l}\text { Chronic Periodontitis Aggressive Periodontitis, Necrotizing Ulcerative Periodontitis, Periodontal abscess, peri-implantitis are infections which could } \\
\text { be considered as "oral foci". }\end{array}$ \\
\hline 24. & Plaque-related Gingivitis, Plaque related Mucositis are periodontal infections which could be considered as "oral foci. \\
\hline 25. & $\begin{array}{l}\text { To assess endodontic infection, at least } 4 \text { intraoral Periapical x-rays should be acquired. If clinical examination shows large carious lesions } \\
\text { restorations on anterior teeth, and in all situations where it is deemed necessary, additional intraoral Periapical } x-\text { rays should be acquired. In the } \\
\text { alternative, if it is not possible to perform intraoral Rx, Digital Panorex with periapical x-rays on target areas should be acquired. }\end{array}$ \\
\hline 26. & $\begin{array}{l}\text { Digital Panorex with periapical x-rays on target areas, full mouth series of Periapical } x \text {-rays should be used to assess the presence of periodontal } \\
\text { infection. }\end{array}$ \\
\hline 27. & At least two pulp sensitivity tests are required to assess pulp necrosis. \\
\hline 28. & $\begin{array}{l}\text { Pulp necrosis, Apical Periodontitis, Acute Apical Abscess, Chronic Apical Abscess are the endodontic infections which should be considered "oral } \\
\text { foci". }\end{array}$ \\
\hline 29. & $\begin{array}{l}\text { If periodontitis is suspected, based upon clinical examination, periapical radiographs of the area of interest may be adequate. In case of more } \\
\text { generalized periodontal a complete series of intraoral radiographs should be taken. }\end{array}$ \\
\hline 30. & The dental protocol should be different depending on the fact that the patient is undergoing CV surgery within a month or within six months. \\
\hline 31. & The radiographic exams available are equally reliable to detect endodontic conditions which can be considered foci of infections. \\
\hline 32. & To assess endodontic infection, the possibility of using Cone beam computed tomography (CBCT) should be considered. \\
\hline 33. & Symptomatic patients with moderate-to-severe aortic stenosis have a poor prognosis at 5-years follow up, even when medically treated. \\
\hline 34. & Asymptomatic patients with chronic severe degenerative mitral regurgitation have a decidedly poor prognosis at 5-years follow up. \\
\hline 35. & $\begin{array}{l}\text { Patients with low ejection fraction (i.e. symptomatic), regardless of ischemic or non-ischemic etiology of functional mitral regurgitation, have a high } \\
\text { rate of mortality at 5-years follow up. }\end{array}$ \\
\hline 36. & $\begin{array}{l}\text { Untreated acquired mitral stenosis due to rheumatic heart disease follows a slowly progressive course, with the patient remaining asymptomatic } \\
\text { for years and with an excellent 10-year survival. }\end{array}$ \\
\hline 37. & $\begin{array}{l}\text { The prognosis in patients with tricuspid regurgitation is generally good, apart from for patients with accompanying pulmonary hypertension or } \\
\text { cardiac dysfunction/dilatation, whose prognosis is directly related to the prognosis for above stated conditions. }\end{array}$ \\
\hline 38. & $\begin{array}{l}\text { In case of aortic surgery, even if the likelihood of oral infection foci leading to prosthesis infection is relatively low, prophylactic treatment of dental } \\
\text { sepsis might eliminate at least one source of aortic prosthetic infection and should therefore be strongly. }\end{array}$ \\
\hline & $\begin{array}{l}\text { In case of cv implantable electronic devices, a connection between their infection and poor oral health has not been established, so that measures } \\
\text { focused on promoting dental hygiene are negligible. }\end{array}$ \\
\hline
\end{tabular}

Fig. 2. Questionnaire.

\subsection{Data analysis}

The responses to the online questionnaire were analyzed by the external non-voting member of the panel (GC). The scores assigned to the answers were reported as medians and 20th and 80th percentiles. Additionally, the scores were grouped into low (1-3), intermediate (4-7), and high ( $8-10)$, and verified by the correspondence analysis. Both approaches were used to identify answers that provided clear-cut responses from the experts, particularly those polarized on agreement or disagreement. Correspondence analysis (Chi square tests) was used to assess if individual panel members provided specific response patterns, particularly when intermediate positions were taken.

The results of the analyses were returned to the panel anonymously (the name of each member was replaced with a numeric code), and the same list of questions was then resubmitted to the panel for a second round of voting.

\subsection{Developing the consensus report}

Based on the analysis of the second round of questions, consensus statements were formulated by the chairs by selecting questions with greater degrees of agreement. A general round table discussion was then held and moderated by the two main authors (GM, EC). The differences between the two groups and between the participants were discussed. To minimize the risk of misinterpretations of some questions and statements, individual panel members who had provided heterogeneous answer patterns were invited to present and review their responses and confirm or change their vote.

After the final round of voting, the consensus was finalized as follows:

- a strong recommendation (in favour or against) was made when $\gg 80 \%$ of the voting members supported this position for a particular question; 
- a weak recommendation was made when the votes in favour or against (a combination of strong and weak options) reached the $80 \%$ threshold:

- a "no recommendation" option was adopted when the $80 \%$ threshold was not reached.

If panel members had minor concerns about specific question, they were permitted to declare their reservations. No blocking options were allowed in case of major concerns, but a stand-alone position was adopted in the presence of the reported concern.

\section{Results}

The answers to the questionnaire revealed a substantial level of degree of agreement ( $\gg 80 \%$ ) of the panel for questions $1-4,6-9,13-14$, $19,21-24,27-28$, and $30-32$, in both groups. Owing to intra- and inter-groups variability in opinion for several items, the degree of agreement was lower than anticipated $\left(\chi^{2}=4.48 \mathrm{p} \ll 0.01\right)$ (Table 1$)$.

Following the plenary discussion, a substantial level of agreement was reached on all the items making it possible to answer each of the clinical questions formulated following the systematic review.

1. Establish a standardized clinical protocol for the assessment of the presence of infections of dental origin in a patient scheduled to undergo elective cardiac surgery or other invasive CV interventions.

Table 1

Agreement scores between the two panels for the various items in the questionnaire.

\begin{tabular}{|c|c|c|}
\hline \multirow[t]{2}{*}{ Items } & \multicolumn{2}{|c|}{ Group } \\
\hline & A & B \\
\hline 1 & $\mathrm{H}$ & $\mathrm{H}$ \\
\hline 2 & $\mathrm{H}$ & $\mathrm{H}$ \\
\hline 3 & $\mathrm{H}$ & I \\
\hline 4 & I & $\mathrm{H}$ \\
\hline 5 & $\mathrm{H}$ & $\mathrm{L}$ \\
\hline 6 & $\mathrm{H}$ & $\mathrm{H}$ \\
\hline 7 & $\mathrm{H}$ & $\mathrm{H}$ \\
\hline 8 & $\mathrm{H}$ & $\mathrm{H}$ \\
\hline 9 & $\mathrm{H}$ & $\mathrm{H}$ \\
\hline 10 & $\mathrm{H}$ & $\mathrm{L}$ \\
\hline 11 & $\mathrm{~L}$ & I \\
\hline 12 & I & I \\
\hline 13 & $\mathrm{H}$ & $\mathrm{H}$ \\
\hline 14 & $\mathrm{H}$ & $\mathrm{H}$ \\
\hline 15 & I & $\mathrm{L}$ \\
\hline 16 & $\mathrm{~L}$ & $\mathrm{~L}$ \\
\hline 17 & I & I \\
\hline 18 & I & I \\
\hline 19 & $\mathrm{H}$ & $\mathrm{H}$ \\
\hline 20 & $\mathrm{H}$ & $\mathrm{H}$ \\
\hline 21 & $\mathrm{H}$ & $\mathrm{H}$ \\
\hline 22 & $\mathrm{H}$ & $\mathrm{H}$ \\
\hline 23 & $\mathrm{H}$ & $\mathrm{H}$ \\
\hline 24 & $\mathrm{H}$ & $\mathrm{H}$ \\
\hline 25 & $\mathrm{~L}$ & $\mathrm{H}$ \\
\hline 26 & $\mathrm{H}$ & $\mathrm{H}$ \\
\hline 27 & $\mathrm{H}$ & $\mathrm{H}$ \\
\hline 28 & $\mathrm{H}$ & $\mathrm{L}$ \\
\hline 29 & I & $\mathrm{H}$ \\
\hline 30 & $\mathrm{H}$ & $\mathrm{H}$ \\
\hline 31 & $\mathrm{H}$ & $\mathrm{H}$ \\
\hline 32 & $\mathrm{H}$ & $\mathrm{H}$ \\
\hline 33 & $\mathrm{H}$ & $\mathrm{H}$ \\
\hline 34 & $\mathrm{H}$ & $\mathrm{H}$ \\
\hline 35 & $\mathrm{H}$ & $\mathrm{H}$ \\
\hline 36 & $\mathrm{H}$ & $\mathrm{H}$ \\
\hline 37 & $\mathrm{H}$ & $\mathrm{H}$ \\
\hline 38 & $\mathrm{H}$ & $\mathrm{H}$ \\
\hline 39 & $\mathrm{H}$ & $\mathrm{H}$ \\
\hline
\end{tabular}

Legends of the agreement: L, low (1-3); I, intermediate (4-7); H, high (8-10).
Table 2

Basic protocol for the accurate screening of periodontal, peri-implant and endodontic infections (oral foci of infection).

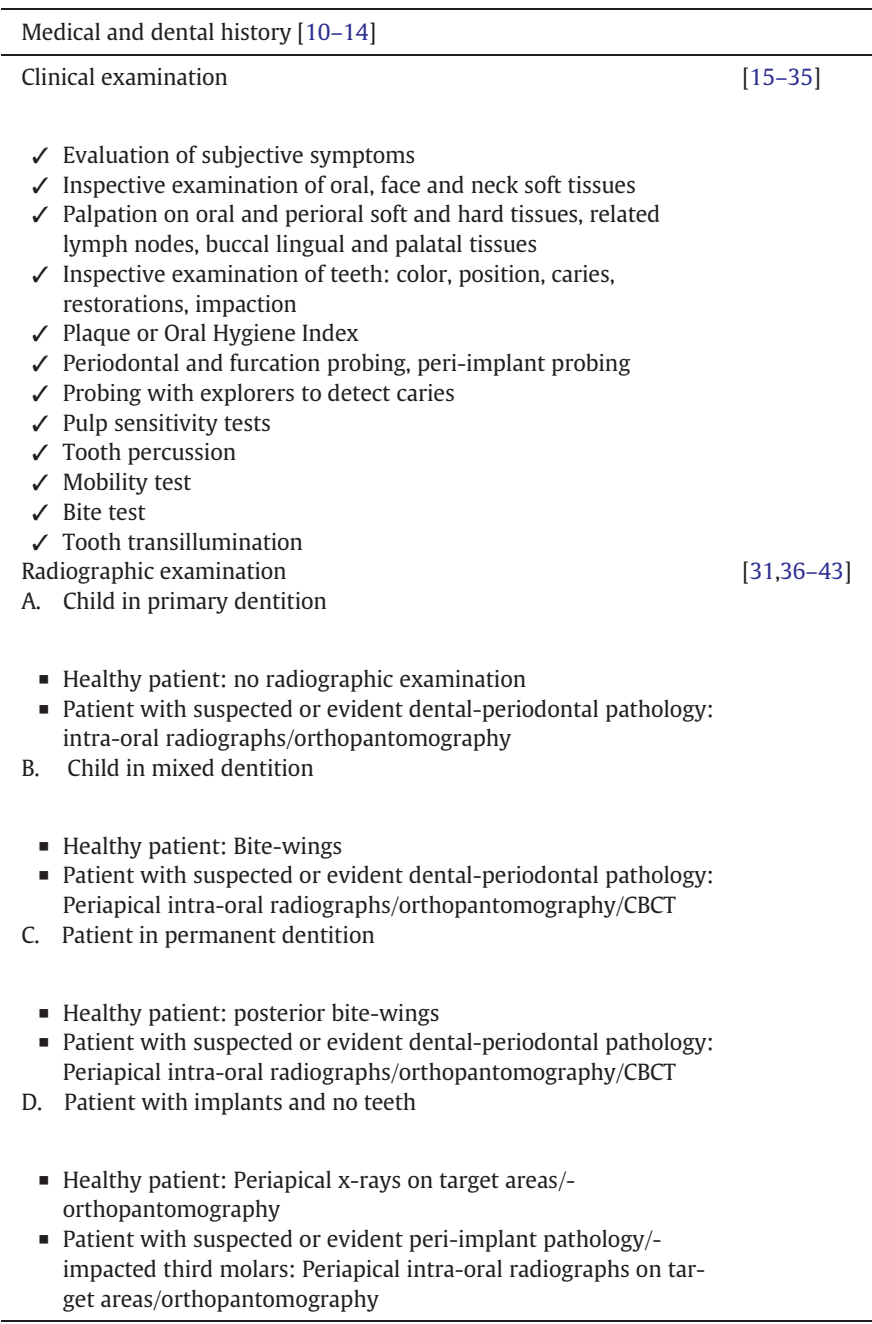

The protocol for the clinical and radiographic evaluation of dental/ periodontal infections, as described in document $\mathrm{A}$ (and confirmed by the consensus achieved), is presented in Table 2. Table 2 is designed to serve as a template for a clinical chart, which will enable dentists to perform a rigorous oral and dental/periodontal examination, based on the best scientific evidence identified by working group A (Table 2). This chart includes a checklist that may favour the assessment of the most important oral infections and places particular emphasis on the choice of clinical diagnostic tools and specific radiographic examinations depending on the status of the individual patient.

2. Identify the average medical conditions of patients and the time available for dental care (to decide whether the dental/periodontal treatment necessary can be performed without harming them) depending on their physical condition.

The most common cardiac conditions that require CV interventions, the waiting time available for the procedures, and their prognoses are listed in Table 3. This scheme is based on the first part of the document produced by group $B$, according to the best scientific evidence available (Table 3).

3. Identify the periodontal and endodontic conditions that should be considered as foci of infection, before performing the $\mathrm{CV}$ procedures, the available treatment options, their outcomes, and the follow-up time needed to assess whether the infection has healed. 
Table 3

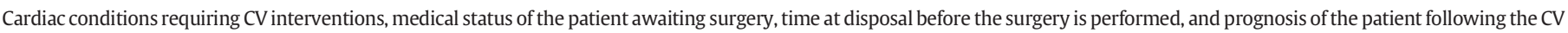
intervention.

\begin{tabular}{|c|c|c|c|}
\hline Cardiovascular intervention & $\begin{array}{l}\text { Medical condition } \\
\text { of the patient }\end{array}$ & $\begin{array}{l}\text { Time at disposal for dental } \\
\text { screening/treatment before } \\
\text { the intervention }\end{array}$ & Prognosis \\
\hline Heart transplantation [44] & $\begin{array}{l}\text { Extremely } \\
\text { compromised or } \\
\text { end-stage }\end{array}$ & $\ll 6$ months & $\begin{array}{l}\text { Very poor without } \\
\text { surgery }\end{array}$ \\
\hline $\begin{array}{l}\text { Severe aortic stenosis (asymptomatic and without significant coronary artery disease - Medically } \\
\text { treated) [44-47] }\end{array}$ & Stable & $\gg 6$ months & Good $^{\mathrm{a}}$ \\
\hline From moderate to severe aortic stenosis (when symptomatic) & Unstable & $\ll 6$ months & $\begin{array}{l}\text { Poor without } \\
\text { surgery }^{\mathrm{b}} / \mathrm{TAVI}^{\mathrm{c}}\end{array}$ \\
\hline Severe aortic regurgitation (symptomatic or asymptomatic but with decreased ejection) $[44,48,49]$ & Unstable & $\ll 6$ months & $\begin{array}{l}\text { Poor without } \\
\text { surgery }^{\mathrm{b}}\end{array}$ \\
\hline $\begin{array}{l}\text { Aortic surgery (when diameter of the ascending aorta is } \geq 5.5 \mathrm{~cm} \text { in patients with normofunctional } \\
\text { bicuspid or tricuspid aortic valve - when diameter } \geq 5 \mathrm{~cm} \text { in patients with severely insufficient } \\
\text { bicuspid aortic valve - when diameter } \geq 5 \mathrm{~cm} \text { in patients with Marfan's syndrome without } \\
\text { familiarity for aortic dissection - when diameter } \geq 4.5 \mathrm{~cm} \text { in patients with Marfan's syndrome } \\
\text { with familiarity for aortic dissection or rapid annual growth or severe aortic or mitralic } \\
\text { valvulopathy - when diameter } \geq 42 \mathrm{~mm} \text { in patients with Loeys-Dietz syndrome) }\end{array}$ & Unstable & $\ll 6$ months & $\begin{array}{l}\text { Poor (high risk of } \\
\text { aortic dissection) }\end{array}$ \\
\hline Aortic surgery (all the other conditions not previously stated) & Stable & $\gg 6$ months & Good $^{\mathrm{b}}$ \\
\hline Mitral stenosis (due to rheumatic disease and medically treated) $[44,50]$ & Stable & $\gg 6$ months & Good $^{\mathrm{d}}$ \\
\hline Severe mitral regurgitation (asymptomatic, but with decreased ejection fraction) $[44,51,52]$ & Unstable & $\ll 6$ months & $\begin{array}{l}\text { Poor without } \\
\text { surgery }^{\mathrm{e}} / \text { MitraClip }^{\mathrm{f}}\end{array}$ \\
\hline Severe mitral regurgitation (asymptomatic and with preserved ejection fraction) & Stable & $\gg 6$ months & Good $^{\mathrm{d}}$ \\
\hline $\begin{array}{l}\text { Tricuspid regurgitation (due to infection or associated with pulmonary hypertension or right } \\
\text { ventricle dilation/dysfunction) }[44,53]\end{array}$ & Unstable & $\ll 6$ months & Poor without surgery \\
\hline Tricuspid regurgitation (non-infective) & Stable & $\gg 6$ months & Good \\
\hline Electronic device with intracardiac catheter & Stable & $\gg 6$ months & $\begin{array}{l}\text { Good after infected } \\
\text { catheter extraction }\end{array}$ \\
\hline
\end{tabular}

\footnotetext{
a Even though antibiotic prophylaxis is no longer prescribed for patients with structural abnormalities of the valves, it has been postulated that bicuspid aortic valves are at higher risk for infective endocarditis compared with normal trileaflets valves [54].

b There are no data comparing aortic valve replacement and valvuloplasty repair in terms of infective endocarditis first appearance, incidence and prevalence. Conversely, in case of

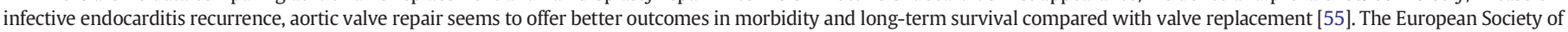

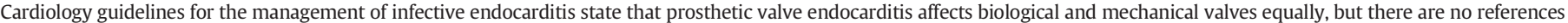

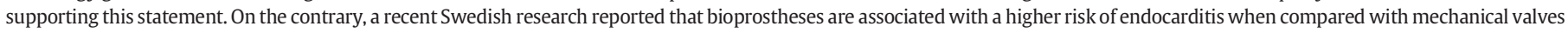
[54].

c Acronym: TAVI (Transcatheter Aortic Valve Implantation). Prosthetic valve endocarditis post TAVI occurs with an incidence ranging from $0.3 \%$ to $1.2 \%$ per patient/year, thus presenting comparable rates with prosthetic valve endocarditis after surgery [56].

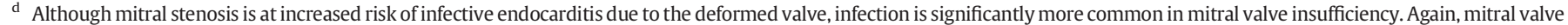
is more susceptible to shear stresses and sluggish blood flow than aortic valve, which is why it is more susceptible to endocarditis [57].

e There are no data comparing mitral valve replacement and valvuloplasty repair in terms of infective endocarditis first appearance incidence and prevalence. On the contrary, in case of infective endocarditis recurrence, mitral valve repair seems to offer better outcomes in morbidity and long-term survival compared with valve replacement [55]

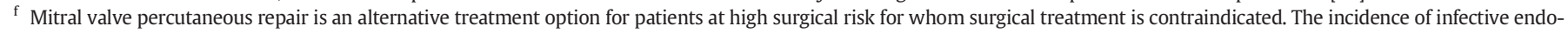
carditis after MitraClip is decidedly lower compared with surgery, but its relevance is high owing to its high mortality [77].
}

Using the scientific evidence gathered in Part II of document B, the group designed a table describing the dental/periodontal infections that should be identified and treatments before the interventional CV procedures are administered, the time needed to evaluate their healing, and their prognoses. This information is summarized in Table 4.

\section{Discussion}

There is general agreement in many European Countries and in the United States on the need for the early screening and resolution of dental/periodontal infections before patients undergo interventional CV procedures, even if this agreement does not seem to be predicated on sound scientific evidence [8]. However, the societies that created the relevant guidelines, did not provide details of a reliable screening process to diagnose foci of infection of oral/dental origin requiring treatment [3]. In other words, foci of infections were never specified. Furthermore, the literature expressing the ratio of risks of inducing bacteremia to the benefits of treating these patients to eliminate dental infection is controversial [8]. As a consequence, communication between the various specialists involved in these complex clinical situations is uncommon. Usually the dentist is not fully informed about the severity of the disease affecting the CV patient, nor on the time available to perform and complete the required treatment. The CV surgeon and interventional cardiologist, in turn, are unaware of the real potential that some dental treatments have for controlling an oral/dental infection, nor of the time required to administer the proper treatment and verify healing. This lack of communication tends to create false expectations on behalf of the cardiologists and cardiac surgeons on the time required to complete a given dental procedure and to assess that it has successfully resolved the infection.

For this consensus project, the RAND/UCLA method was selected, based on the integration of evidence from the literature review and expert opinions. The value of the RAND/UCLA method is improved when the results from a systematic review are incorporated, and the panel meeting is considered an added value that allows the experts involved to discuss the ratings and the judgements [6]. In the present study, the consensus process resulted in a standardized screening protocol for evaluating, with a coherent method, the presence of oral/dental infection in the CV patient.

Infections of dental/periodontal origin that should be considered have been identified and their treatments and prognoses have been schematized. The adoption and dissemination of this protocol should eliminate inconsistencies between screenings performed in various locations and by various professionals, ensuring an appropriate ratio between the time involved and the benefit for the patient.

A snapshot of the cardiac conditions requiring invasive interventions, and of the related medical status of the patient, according to the severity of the disease, and of the waiting time for the intervention has also been created. Based on this readily available information, dentists can evaluate the benefit-to-risk ratio before proceeding with 
Table 4

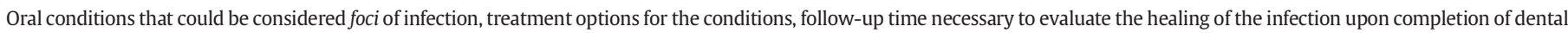
treatment.

\begin{tabular}{|c|c|c|c|}
\hline Infection & Treatment options & $\begin{array}{l}\text { Follow-up } \\
\text { time }^{\mathrm{a}}\end{array}$ & Prognosis \\
\hline $\begin{array}{l}\text { Plaque-related gingivitis/mucositis } \\
\text { [58,59] }\end{array}$ & Professional oral hygiene procedures - improvement of self-performed procedures & 3 days & $\gg 95 \%$ \\
\hline $\begin{array}{l}\text { Chronic periodontitis or periodontitis } \\
\text { with low-moderate progression [60] }\end{array}$ & $\begin{array}{c}\text { Multiple - 4/6 - professional oral hygiene procedures - improvement of self-performed } \\
\text { procedures - possible periodontal surgery }\end{array}$ & $\begin{array}{l}6-8 \text { weeks } \\
6 \text { months } \\
\text { (after } \\
\text { surgery) }\end{array}$ & $\gg 90 \%$ \\
\hline $\begin{array}{l}\text { Aggressive periodontitis or } \\
\text { periodontitis with rapid progression } \\
{[60]}\end{array}$ & Treatment as for chronic periodontitis + systemic antibiotics strongly recommended & $\begin{array}{l}6-8 \text { weeks } \\
6 \text { months } \\
\text { (after } \\
\text { surgery) }\end{array}$ & $\gg 70 \%$ \\
\hline $\begin{array}{l}\text { Necrotizing ulcerative periodontitis } \\
{[61,78]}\end{array}$ & Treatment as for chronic periodontitis + systemic antibiotics strongly recommended & 1 week & $\gg 90 \%$ \\
\hline $\begin{array}{l}\text { Periodontitis associated with systemic } \\
\text { diseases [62] }\end{array}$ & Treatment is as for chronic periodontitis, but systemic antibiotics may be recommended & $6-8$ weeks & $\begin{array}{l}\text { Long-term prognosis } \\
\text { still unknown }\end{array}$ \\
\hline Periodontal abscess [63] & $\begin{array}{c}\text { Mechanical treatment }+ \text { systemic antibiotics - re-evaluation - causal related treatment and } \\
\text { surgical treatment }\end{array}$ & $7-10$ days & $\begin{array}{l}\ll<0 \% \\
\text { with indications for } \\
\text { extraction }\end{array}$ \\
\hline Peri-implantitis [64] & $\begin{array}{c}\text { Mechanical removal of plaque-improvement of self-performed procedures - Systemic } \\
\text { antibiotics may be indicated - Re-evaluation possible periodontal surgery, possible implant } \\
\text { extraction }\end{array}$ & $\begin{array}{l}6 \text {-8 weeks } \\
6 \text { months } \\
\text { (after } \\
\text { surgery) }\end{array}$ & $\begin{array}{l}\gg 90 \% \\
\quad \text { (if supportive } \\
\text { periodontal therapy } \\
\text { performed) }\end{array}$ \\
\hline Irreversible pulpitis [65-68] & $\begin{array}{l}\text { Removal of caries; primary root canal treatment }+ \text { tooth restoration - Alternative extraction - } \\
\text { Non-steroidal anti-inflammatory drugs may be administered }\end{array}$ & $\begin{array}{l}1 \text { week (for } \\
\text { symptoms) }\end{array}$ & $\gg 90 \%$ \\
\hline Pulp necrosis [65] & $\begin{array}{l}\text { Removal of caries; primary root canal treatment }+ \text { tooth restoration. Alternative extraction - } \\
\text { Non-steroidal anti-inflammatory drugs may be administered. }\end{array}$ & $\begin{array}{l}1 \text { week (for } \\
\text { symptoms) }\end{array}$ & $\gg 90 \%$ \\
\hline Apical periodontitis [66-74] & $\begin{array}{c}\text { Removal of caries; primary or secondary root canal treatment }+ \text { tooth restoration - Alternative } \\
\text { endodontic surgery or extraction }\end{array}$ & $\begin{array}{c}1 \text { week (for } \\
\text { symptoms) } \\
1 \mathrm{yr}\end{array}$ & $75-80 \%$ \\
\hline Acute apical abscess [75] & Same as for apical periodontitis - possible incision and drainage and/or systemic antibiotics & $\begin{array}{c}1 \text { week (for } \\
\text { symptoms) } \\
1 \mathrm{yr}\end{array}$ & $75-80 \%$ \\
\hline Chronic apical abscess [76] & Same as for apical periodontitis & $\begin{array}{c}1 \text { week (for } \\
\text { symptoms) } \\
1 \mathrm{yr}\end{array}$ & $\ll 80 \%$ \\
\hline
\end{tabular}

a Follow-up time refers to average time required to evaluate the benefits of treatment

(radical) dental treatment, plan an appropriate therapeutic programme and establish a useful collaboration with the referring cardiologist.

In the light of the documents produced and the substantial level of agreement reached in this consensus, the following recommendations are made:

\subsection{Advantages for dental practitioners}

- If the dental practitioners, when asked to assess the presence of oral/ dental infections in a patient awaiting cardiac surgery or an interventional CV procedure, follow the screening process suggested in this consensus, it is more likely that dental pathoses will be identified because it is based on a logical and systematic checklist approach for a dental/periodontal evaluation.

- They would have a rational approach to the most common dental/periodontal conditions to consider as a potential source of infection, their treatment options, the timing of the intervention and the prognosis.

- They would be more likely aware of the actual medical conditions of the patient waiting for a given CV intervention, be able to plan a dental intervention accordingly, and operate with optimal communication with the referring cardiologist, well aware that the dental/periodontal treatments in these subjects may take time, or even create complications.

\subsection{Advantages for cardiac surgeons and cardiologists}

- Cardiac surgeons and cardiologists would be able to verify that dental screening of these patients referred for a pre-interventional evaluation of oral infections has been completed.

- They may, at the same time, become familiar with the type of dental/ periodontal treatment that has to be administered in a given situation, its predictability, and the time required for it to be completed and declared successful.

As a general rule, it is the underlying cardiovascular pathosis that influences the time available for dental treatment, rather than the type of intervention required (valve surgical replacement, surgical valvuloplasty, percutaneous intervention). However, the intervention plays a significant role regarding susceptibility to primary infective endocarditis, its outcomes, and possible recurrence.

Even if the guidelines are not as effective as the authors anticipate [9], the information gathered and approved in this document, in conjunction with closer cooperation between cardiologists, cardiac surgeons and dentists is likely to result in better planning of dental treatment for these fragile patients, with the advantage of the ability to weight risks to benefits of the intervention.

\subsection{Recommendations for research}

The panel of experts recognizes that based on the information gathered during this consensus process further research is needed to:

- Better understand which dental/periodontal infections may increase significantly the risk of infection for patients undergoing invasive CV interventions;

- Identify the risks and benefits related to dental treatment before CV interventions;

- Evaluate whether dental treatment in these scenarios should be radical or conservative. 
The development of this consensus report is only a first step, the next critical phase being the implementation of its suggestions. This will require further work by those interested in this complex field in order to change clinical behaviour and modify clinical practice that historically may not have been cost-effective or of real benefit to patients.

\section{Conclusions}

The authors anticipate this consensus process can be a model for the development of a dedicated protocol, ideally usable by heart and dental teams in the pre-interventional preparation phase. Upon the publication of this Consensus document, the dissemination of the information to a wide audience should commence. Dedicated informative/educational material will be produced by the scientific societies involved in this document, and in particular a standardized clinical chart (as in Table 2) designed to complete a predictable evaluation on each patient will be created.

The material will be sent to Dental Schools, Dental Societies, Medical Schools, Cardiac/Cardiac Surgery Societies in Italy. Continuing medical education initiatives will need to be updated for consistency with the consensus. Sessions to share and explain this consensus will be planned during future scientific meetings of the dental and cardiologic associations to inform clinicians in both specialties. Hopefully this step will be joined internationally (with appropriate adaptation/changes).

\section{Acknowledgements}

All author takes responsibility for all aspects of the reliability and freedom from bias of the data presented and their interpretation. There was no industry input into the development of this consensus report and no panel member received an honorarium.

\section{Conflict of interest}

The authors have stated explicitly that there are no conflicts of interest in connection with this article.

\section{References}

[1] G. Habib, P. Lancellotti, M.J. Antunes, et al., 2015 ESC Guidelines for the management of infective endocarditis, European Heart Journal 36 (2015) 3075-3123.

[2] W. Wilson, K.A. Taubert, M. Gewitz, et al., Prevention of infective endocarditis: guidelines from the American Heart Association: a guideline from the American Heart Association Rheumatic Fever, Endocarditis, and Kawasaki Disease Committee, Council on Cardiovascular Diseases in the Young, and the Council on Clinical Cardiology, Council on Cardiovascular Surgery and Anesthesia, and the Quality of Care and Outcomes Research Interdisciplinary Working Group, Circulation 116 (2007) 1736-1754.

[3] N. Gandhi, G. Silvay, How important is dental clearance for elective open heart operations? Annals of Thoracic Surgery 99 (2015) 377.

[4] J.S. Yasny, A. Herlich, Perioperative dental evaluation, Mount Sinai Journal of Medicine 79 (2012) 34-45.

[5] G. Silvay, M. Khromava, M. Weiner, A. Goldberg, Is dental evaluation before cardiac and aortic surgery needed? A review communication, Developments in anaesthetics and pain management 1 (2018) 1-3

[6] Fitch K, Bernstein S J, Aguilar MD, et al. The RAND/UCLA Appropriateness Metho User's Manual. RAND Publishing, 2001, Santa Monica, CA RAND URL: http://www. rand.org

[7] F. Bourrée, P. Michel, L.R. Salmi, Consensus methods: review of original methods and their main alternatives used in public health, Revue d' Epidemiologie et de Sante Publique 56 (2008) e13-e21.

[8] E. Cotti, M. Arrica, A. Di Lenarda, et al., The perioperative dental screening and management of patients undergoing cardiothoracic, vascular surgery and other cardiovascular invasive procedures: a systematic review, European Journal of Preventive Cardiology 24 (2017) 409-425.

[9] J. Gabbay, A. le May, Mindlines: making a sense of evidence in practice, British Journal of General Practice 66 (2016) 402-403.

[10] R.J. Genco, W.S. Borgnakke, Risk factors for periodontal disease, Periodontology 200062 (2013) 59-94.

[11] A. Veitz-Keenan, A.M. De Bartolo, Insufficient evidence of the effect of systemic antibiotics on adults with symptomatic apical periodontitis or acute apical abscess, Evidence Based Dentistry 15 (2014) 104-105.

[12] B.R. Chrcanovic, A history of periodontitis suggests a higher risk for implant loss, Journal of Evidence Based Dental Practice 15 (2015) 185-186.
[13] S. Jepsen, T. Berglundh, R. Genco, et al., Primary prevention of peri-implantitis: managing peri-implant mucositis, Journal of Clinical Periodontology 42 (S16) (2015) S152-S157.

[14] E.T. Knight, J. Liu, G.J. Seymour, C.M. Faggion, M.P. Cullinan, Risk factors that may modify the innate and adaptive immune responses in periodontal diseases, Periodontology 200071 (2016) 22-51.

[15] Muhlemann HR (1967) Tooth mobility: a review of clinical aspects and research findings. Journal of Periodontology 38, Suppl: 686-713.

[16] N.P. Lang, R. Adler, A. Joss, et al., Absence of bleeding on probing, An indicator of periodontal stability. Journal of Clinical Periodontology 38 (1972) 38

[17] T.J. O'Leary, R.B. Drake, J.E. Naylor, et al., The plaque control record, Journal of Clinical Periodontology 17 (Suppl) (1972) 686-713.

[18] J.H. Simon, D.H. Glick, A.L. Frank, The relationship of endodontic-periodontic lesions, Journal of Periodontology 43 (1972) 202-208.

[19] S.E. Hamp, S. Nyman, J. Lindhe, Periodontal treatment of multirooted teeth. Results after 5 years, Jornal of Clinical Periodontology 2 (1975) 126-135.

[20] D. Tarnow, P. Fletcher, Classification of the vertical component of furcation involvement, Journal of Periodontology 55 (1984) 283-294.

[21] N.P. Lang, A. Joss, T. Orsanic, F.A. Gusberti, B.E. Siegrist, Bleeding on probing. A predictor for the progression of periodontal disease? Journal of Clinical Periodontoogyl 13 (1986) 590-596.

[22] M.C. Downer, Validation of methods used in dental caries diagnosis, International Dental Journal 39 (1989) 241-246.

[23] K. Petersson, C. Söderström, M. Kiani-Anaraki, G. Lévy, Evaluation of the ability of thermal and electrical tests to register pulp vitality, Endodontics and Dental Traumatology 15 (1999) 127-131.

[24] R.G. Landry, M. Jean, Periodontal Screening and Recording (PSR) Index: precursors, utility and limitations in a clinical setting, International Dental Journal 52 (2002) 35-40.

[25] J.C. Hamilton, Should a dental explorer be used to probe suspected carious lesions? Yes-an explorer is a time-tested tool for caries detection. Journal of American Dental Association 136 (2005) 1526-1528.

[26] I. Abrahamsson, C. Soldini, Probe penetration in periodontal and peri-implant tissues: an experimental study in the beagle dog, Clinical Oral Implants Research 1 (2006) 601-605.

[27] P. Linsuwanont, J.E.A. Palamara, H.H. Messer, An investigation of thermal stimulation in intact teeth, Archives of Oral Biology 52 (2007) 218-227.

[28] J.L. Gutmann, J.C. Baumgartner, A.H. Gluskin, G.R. Hartwell, R.E. Walton, Identify and define all diagnostic terms for periapical/periradicular health and disease states, Journal of Endodontics 35 (2009) 1658-1674.

[29] L.G. Levin, A.S. Law, G.R. Holland, P.V. Abbott, R.S. Roda, Identify and define all diagnostic terms for pulpal health and disease states, Journal of Endodontics 35 (2009) $1645-1657$.

[30] U. Van Der Velden, The Dutch periodontal screening index validation and its application in the Netherlands, Journal of Clinical Periodontology 36 (2009) 1018-1024.

[31] C.W. Newton, M.M. Hoen, H.E. Goodis, B.R. Johnson, S.B. McClanahan, Identify and determine the metrics, hierarchy, and predictive value of all the parameters and/ or methods used during endodontic diagnosis, Journal of Endodontics 35 (2009) 1635-1644.

[32] F. Graziani, E. Figuero, D. Herrera, Systematic review of quality of reporting, outcome measurements and methods to study efficacy of preventive and therapeutic approaches to peri-implant diseases, Journal of Clinical Periodontology 39 (Suppl. 12) (2012) 224-244.

[33] D.R. Nixdorf, A.S. Law, M.T. John, R.M. Sobieh, R. Kohli, R.H.N. Nguyen, Differential diagnoses for persistent pain after root canal treatment: a study in the national dental practice-based research network, Journal of Endodontics 41 (2015) 457-463.

[34] M. Sanz, A. Bäumer, N. Buduneli, H. Dommisch, R. Farina, E. Kononen, G. Linden, J. Meyle, P.M. Preshaw, M. Quirynen, S. Roldan, N. Sanchez, A. Sculean, D.E. Slot, L. Trombelli, N. West, E. Winkel, Periodontal treatment of multirooted teeth, Results after 5 years. Journal of Clinical Periodontology 42 (2015) S214-S220.

[35] C. Lara-Capi, M.G. Cagetti, P. Lingström, G. Lai, F. Cocco, C. Simark-Mattsson, G. Campus, Digital transillumination in caries detection versus radiographic and clinical methods: an in-vivo study, Dentomaxillofacial Radiology 46 (2017) 1-8.

[36] W.H. Abu El-Ela, M.M. Farid, M.S.E.-D. Mostafa, Intraoral versus extraoral bitewing radiography in detection of enamel proximal caries: an ex vivo study, Dentomaxillofacial Radiology 45 (2016) 20150326.

[37] N.K. Chugh, J. Bhattacharyya, S. Das, S. Ghosh, K. Dutta, P. Goel, Use of digital panoramic radiology in presurgical implant treatment planning to accurately assess bone density, Journal of Prosthetic Dentistry 116 e1 (2016) 200-205.

[38] H. Long, Y. Zhou, N. Ye, et al., Diagnostic accuracy of CBCT for tooth fractures: a meta-analysis, Journal of Dentistry 42 (2014) 240-248.

[39] K.M.T. Low, K. Dula, W. Bürgin, T. von Arx, Comparison of periapical radiography and limited cone-beam tomography in posterior maxillary teeth referred for apical surgery, Journal of Endodontics 34 (2008) 557-562.

[40] F.J. Mota De Almeida, K. Knutsson, L. Flygare, The effect of cone beam CT (CBCT) on therapeutic decision-making in endodontics, Dentomaxillofacial Radiology 43 (2014) 2013-2037.

[41] S. Patel, R. Wilson, A. Dawood, F. Mannocci, The detection of periapical pathosis using periapical radiography and cone beam computed tomography - part 1: preoperative status, International Endodontic Journal 45 (2012) 702-710.

[42] F.W.G. de Paula-Silva, M.K. Wu, M.R. Leonardo, L.A. Bezerra da Silva, P.R. Wesselink, Accuracy of periapical radiography and cone-beam computed tomography scans in diagnosing apical periodontitis using histopathological findings as a gold standard, Journal of Endodontics 35 (2009) 1009-1012. 
[43] E.A. Pepelassi, A. Diamanti-Kipioti, Selection of the most accurate method of conventional radiography for the assessment of periodontal osseous destruction, Journal of Clinical Periodontology 24 (1997) 557-567.

[44] H. Baumgartner, V. Falk, J.J. Bax, et al., ESC Scientific Document Group. 2017 ESC/ EACTS Guidelines for the management of valvular heart disease, European Heart Journal 38 (2017) 2739-2791.

[45] Topol EJ, Califf RM, et al, eds. (2007) Aortic valve disease. Textbook of Cardiovascular Medicine. Section Two. 3rd ed. Philadelphia, Pa: Lippincott Williams \& Wilkins, chapter 23.

[46] N. Jander, J. Minners, I. Holme, E. Gerdts, K. Boman, P. Brudi, J.B. Chambers, K. Egstrup, Y.A. Kesäniemi, W. Malbecq, C.A. Nienaber, S. Ray, A. Rossebø, T.R. Pedersen, T. Skjærpe, R. Willenheimer, K. Wachtell, F.J. Neumann, C. GohlkeBärwolf, Outcome of patients with low-gradient "severe" aortic stenosis and preserved ejection fraction, Circulation 123 (2011) 887-895.

[47] P. Lancellotti, J. Magne, E. Donal, et al., Clinical outcome in asymptomatic severe aortic stenosis: insights from the new proposed aortic stenosis grading classification, Journal of the American College of Cardiology 59 (2012) 235-243.

[48] A. Lauten, H.R. Figulla, Interventions at the tricuspid valve: what is possible? Herz 40 (2015) 759-764.

[49] Y. Sato, M. Izumo, K. Suzuki, et al., Prognostic value of exercise left ventricular endsystolic volume index in patients with asymptomatic aortic regurgitation: an exercise echocardiography study, Journal of Echocardiography 15 (2017) 70-78.

[50] C.J. Bruce, R.A. Nishimura, Clinical assessment and management of mitral stenosis, Cardiology Clinics 16 (1998) 375-403.

[51] A. Rossi, F.L. Dini, P. Faggiano, E. Agricola, M. Cicoira, S. Frattini, A. Simioniuc, M. Gullace, S. Ghio, M. Enriquez-Sarano, P.L. Temporelli, Independent prognostic value of functional regurgitation in patients with heart failure. A quantitative analysis of 1256 patients with ischaemic and non-ischaemic dilated cardiomyopatthy, Heart 97 (2011) 1675-1680.

[52] C. Tribouilloy, F. Grigioni, J.F. Avierinos, A. Barbieri, D. Rusinaru, C. Szymanski, M. Ferlito, L. Tafanelli, F. Bursi, F. Trojette, A. Branzi, G. Habib, M.G. Modena, M. Enriquez-Sarano, MIDA Investigators, Survival implication of left ventricular endsystolic diameter in mitral regurgitation due to flail leaflets a long-term follow-up multicenter study. Journal of the American College of Cardiology 54 (2009) 1961-1968.

[53] Y. Topilsky, A.D. Khanna, J.K. Oh, R.A. Nishimura, M. Enriquez-Sarano, Y.B. Jeon, T.M. Sundt, H.V. Schaff, S.J. Park, Preoperative factors associated with adverse outcome after tricuspid valve replacement, Circulation 123 (2011) 1929-1939.

[54] N. Glaser, V. Jackson, M.J. Holzmann, A. Franco-Cereceda, U. Sartipy, Prosthetic valve endocarditis after surgical aortic valve replacement, Circulation 136 (2017) 329-331.

[55] D. Zhao, B. Zhang, Are valve repairs associated with better outcomes than replacements in patients with native active valve endocarditis? Interactive CardioVascular and Thoracic Surgery 19 (2014) 1036-1039.

[56] I.J. Amat-Sandos, D. Messika-Zeitoun, H. Eltchaninoff, et al., Infective endocarditis following transcatheter aortic valve implantation: results from a large multicenter registry, Circulation 131 (2015) 1566-1574.

[57] M.H. Thornhill, S. Jones, B. Prendergast, L.M. Baddour, J.B. Chambers, P.B. Lockhart, M.J. Dayer, Quantifying infective endocarditis risk in patients with predisposing cardiac conditions, European Heart Journal 39 (2018) 586-955.

[58] H. Loe, E. Theilade, S.B. Jensen, Experimental gingivitis in man, Journal of Periodontology 36 (1965) 177-187.

[59] R. Pontoriero, M.P. Tonelli, G. Carnevale, A. Mombelli, S.R. Nyman, N.P. Lang, Experimentally induced peri-implant mucositis. A clinical study in humans, Clinical Oral Implants Research 5 (1994) 254-259.
[60] P.N. Papapanou, M. Sanz, N. Buduneli, T. Dietrich, M. Feres, D.H. Fine, T.F. Flemmig, R. Garcia, W.V. Giannobile, F. Graziani, H. Greenwell, D. Herrera, R.T. Kao, M. Kebschull, D.F. Kinane, K.L. Kirkwood, T. Kocher, K.S. Kornman, P.S. Kumar, B.G. Loos, E. Machtei, H. Meng, A. Mombelli, I. Needleman, S. Offenbacher, G.J. Seymour, R. Teles, M.S. Tonetti, Periodontitis: consensus report of workgroup 2 of the 2017 World Workshop on the Classification of Periodontal and Peri-Implant Diseases and Conditions, Journal of Clinical Periodontology 45 (Suppl. 20) (2018) S162-S170

[61] R.W. Rowland, Necrotizing ulcerative gingivitis, Annals of Periodontology 4 (1999) 65-73 discussion 78.

[62] D.F. Kinane, Periodontitis modified by systemic factors, Annals of Periodontology 4 (1999) 54-64.

[63] D. Herrera, B. Alonso, L. de Arriba, I. Santa Cruz, C. Serrano, M. Sanz, Acute periodontal lesions, Periodontology 200065 (2014) 149-177.

[64] J. Derks, D. Schaller, J. Håkansson, J.L. Wennström, C. Tomasi, T. Berglundh, Periimplantitis onset and pattern of progression, Journal of Clinical Periodontology 43 (2016) 383-388.

[65] S. Seltzer, I.B. Bender, M. Zionz, The dynamics of pulp inflammation: correlation between diagnostic data and actual histologic findings in the pulp, Oral Surgery 16 (1963) 846-847.

[66] Y.L. Ng, V. Mann, S. Rahbaran, J. Lewsey, K. Gulabivala, Outcome of primary root canal treatment: systematic review of the literature-part 1 . Effects of study characteristics on probability of success, International Endodontic Journal 40 (2007) 921-939.

[67] Y.L. Ng, V. Mann, K. Gulabivala, Outcome of secondary root canal treatment: a systematic review of the literature, International Endodontic Journal 41 (2008) 1026-1046.

[68] Y.L. Ng, V. Mann, S. Rahbaran, J. Lewsey, K. Gulabivala, Outcome of primary root canal treatment: systematic review of the literature-part 2. Influence of clinical factors, International Endodontic Journal 41 (2008) 6-31.

[69] P.N.R. Nair, Apical periodontitis: a dynamic encounter between root canal infection and host response, Periodontology 200013 (1997) 121-148.

[70] F. Gorni, M. Gagliani, The outcome of endodontic retreatment: a 2-yr follow-up, Journal of Endodontics 30 (2004) 1-4.

[71] Y.L. Ng, V. Mann, K. Gulabivala, A prospective study of the factors affecting outcomes of nonsurgical root canal treatment-part 1: periapical health, International Endodontic Journal 44 (2011) 583-609.

[72] Y.L. Ng, V. Mann, K. Gulabivala, A prospective study of the factors affecting outcomes of non-surgical root canal treatment: part 2: tooth survival, International Endodontic Journal 44 (2011) 610-625.

[73] F.C. Setzer, M.R. Kohli, S.B. Shah, et al., Outcome of endodontic surgery: a metaanalysis of the literature-part 2: comparison of endodontic microsurgical techniques with and without the use of higher magnification, Journal of Endodontics 38 (2012) $1-10$.

[74] T. von Arx, S.S. Jensen, S. Hanni, S. Friedman, Five-years longitudinal assessment of the prognosis of apical microsurgery, Journal of Endodontics 38 (2012) 570-579.

[75] J. Baumgartner, T. Xia, Antibiotic susceptibility of bacteria associated with endodontic abscesses, Journal of Endodontics 29 (2003) 44-47.

[76] American Association of Endodontists, Glossary of Endodontic Terms, ed 8, American Association of Endodontists, Chicago, 2012.

[77] N.F. Boeder, O. Dörr, J. Rixe, K. Weipert, T. Bauer, M. Bayer, C.W. Hamm, H.M. Nef, Endocarditis after interventional repair of the mitral valve: review of a dilemma, Cardiovascular Revascularization Medicine 18 (2017) 141-144.

[78] M.J. Novak, Necrotizing ulcerative periodontitis, Annals of Periodontology 4 (1999) 74-78. 